\title{
MUNICIPAL WASTE COLLECTION OF LARGE ITEMS OPTIMIZED WITH ARC GIS NETWORK ANALYST
}

\author{
NIKOLAOS V. KARADIMAS \\ MARIA KOLOKATHI \\ GERASIMOULA DEFTERAIOU \\ VASSILI LOUMOS \\ National Technical University of Athens, Multimedia Technology Laboratory \\ 9 Heroon Polytechneiou, Zografou Campus, 15780 Athens, Greece \\ E-mail:nkaradim@central.ntua.gr,el00666@mail.ntua.gr, \\ e100661@mail.ntua.gr,1oumos@cs.ntua.gr
}

\section{KEYWORDS}

Waste Collection, Large Items, Solid Waste, Optimization, ArcGis, Geographical Information System, Simulation.

\begin{abstract}
In the present paper the ArcGIS Network Analyst Algorithm is introduced for best routing identification applied in municipal waste collection of large items. The proposed application takes into account all the required parameters for the waste collection of large items so as its desktop users to be able to model realistic network conditions and scenarios. In this case, the simulation consists of scenarios of visiting loading spots in the municipality of Athens, in order to collect large items that couldn't be collected by the standard waste collection trucks, due to size and other prohibitive obstacles. The Network Analyst is used to estimate interrelations between the dynamic factors, like network traffic changes (closed roads due to natural or technical causes, for example, fallen trees, car accidents, etc) in the area under study and to produce optimized solutions. The user is able to define or modify all the required dynamic factors for the creation of an initial scenario, and by modifying these particular parameters, alternative scenarios can be generated leading to several solutions. Finally, the optimal solution is identified by a function that takes into consideration various parameters, for example the shortest distance, road network as well as social and environmental implications.
\end{abstract}

\section{INTRODUCTION}

Solid waste management is undoubtedly an increasingly important element in terms of efficiency and profitability for any municipality, particularly in industrialized nations. Its especially complex dimension is a result not only of the direct relationship with a number of factors that originate the living standard of a society, but also of our continuously rising consuming lifestyle which analogically enhances the existing operational difficulties.

Waste collection of large items is one of the major parts of the process of solid waste management which consists of generation, collection, transportation, treatment and final disposal (Modak et al 1996). It is statistically proved that a major proportion of the total cost for solid waste management is spent into municipal solid waste collection (Ludwig et al 1968). Having pinpointed the economic significance of waste collection, it is equally important to underline that it is also one of the most difficult operational problems faced by local authorities in any city. The sheer enormity of the project dictates that well organized, well managed teams perform the necessary duties on a daily basis, in order to sustain the demanding hygienic standards that are expected by the city's residents.

In recent years, due to a number of cost, health, and environmental concerns, many municipalities have been forced to assess their solid waste management and examine its cost-effectiveness and environmental impacts, in terms of designing collection routes. During the last decade, there have been numerous technological advances, new developments, mergers and acquisitions in the waste industry. The result is that both private and municipal haulers are giving serious consideration to new technologies such as computerized vehicle routing software (Nuortioa et al 2005).

In other words, the clients involved in this project have the intention to achieve a mapping solution, which will allow their already existing routes to become more efficient. The optimized routes will result in reducing costs of fuel, costs of labour, ware of trucks and time needed for the waste collection of large items.

The paper is structured in the following sections: Section 2, presents a theoretical overview of the related literature. Section 3 describes the network analyst algorithm and in Section 4 the waste collection of large items management problem in the selected case study area is presented. Section 5 illustrates the proposed solution. Section 6 presents the results while Section 7 is 
devoted to discussion and future works.

\section{RELEVANT WORK}

The routing optimization problem in waste management has been already explored with a number of algorithms. Routing algorithms use a standard of measurement called a metric (i.e. path length) to determine the optimal route or path to a specified destination. Optimal routes are determined by comparing metrics, and these metrics can differ depending on the design of the routing algorithm used (Parker 2001).

The last years, different kind of algorithms have been proposed finding the optimal routes, such as:

- Simulated Annealing is a related global optimization technique which traverses the search space by generating neighbouring solutions of the current solution (Kirkpatrick et al 1983).

- Tabu Search is similar to Simulated Annealing, in that both traverse the solution space by testing mutations of an individual solution. While simulated annealing generates only one mutated solution, tabu search generates many mutated solutions and moves to the solution with the lowest fitness of those generated (Glover et al 1997).

- Genetic algorithms (Holland 1975) use biological methods such as reproduction, crossover, and mutation to quickly search for solutions to complex problems. Genetic algorithm begins with a random set of possible solutions. In each step, a fixed number of the better current solutions are saved and they are used to the next step to generate new solutions using genetic operators.

- The ant colony optimization algorithm which has been used to produce near-optimal solutions to the travelling salesman problem. They have an advantage over simulated annealing and genetic algorithm approaches when the graph may change dynamically (Dorigo et al 1999).

- Dijkstra's algorithm, used by Network Analyst, is a greedy algorithm that solves the single-source shortest path problem for a directed graph with nonnegative edge weights (Dijkstra 1959).

However, Network Analyst is still relatively new software, so there is not much published material concerning its application on solid waste management. Only few researchers during the last years have reported the use of the GIS Network Analyst extension in order to solve solid waste collection problems. Karagiannidis et al (2006) introduce a design and a pilot application of a GIS for the optimization of waste collection in the Municipalities of Panorama and Sikies in the Thessaloniki, Greece. Moreover, Moussiopoulos et al (2006) via GEOLORE (2003) program have estimated the waste quantity produced and optimized the route of a waste collection vehicle within a densely populated area. Miller (2005) compares the RouteSmart 4.40, the ArcLogistics Route and the ArcMap Network Analyst extension on the ability of either software package to create routes usable by the Solid Waste Department in a timely, efficient manner for the city of Richardson in Texas.

\section{NETWORK ANALYST}

ArcGIS Network Analyst is a powerful extension that provides network-based spatial analysis including routing, travel directions, closest facility, and service area analysis. ArcGIS Network Analyst enables users to dynamically model realistic network conditions, including turn restrictions, speed limits, height restrictions, and traffic conditions at different times of the day (ESRI 2006). The users with Network Analyst extension are able to:

- Find efficient travel routes,

- Determine which facility or vehicle is closest,

- Generate travel directions, and

- Find a service area around a site.

In the current work, using Network Analyst, an optimum route for the waste collection of large items is generated in the area under study. Network Analyst uses the Dijkstra's Algorithm (Dijkstra 1959) in order to solve the Routing Problem and it can be generated based on two criteria (Lakshumi et al 2006):

1. Distance criteria: The route is generated taking only into consideration the location of the waste large items. The volume of traffic in the roads is not considered in this case.

2. Time criteria: The total travel time in each road segment should be considered as the: Total travel time in the route $=$ runtime of the vehicle + waste collection of large items time. The runtime of the vehicle is calculated by considering the length of the road and the speed of the vehicle in each road. The time of the waste large items collection would be the total time consumed by the vehicle to collect these objects from all the loading spots In the second criteria, the length, width and the volume of traffic are taken into account in each road segment.

Using the second criteria, several routes could be generated during a random day in order to compare the total travel time between these predefined time intervals. Hence, routes could be generated during the day time or during the night time in order to compare the total travel time in these different time intervals during the day.

The Network Analyst extension allows the user to perform "Find Best Route", which solves a network problem by finding the least cost impedance path on the network from one stop to one or more stops. Network modeling gives the opportunity to the user to include the rules relating to the objects, arcs and events in association with solving transportation problems (Stewart 2004). 


\section{The Path finding Algorithm}

Network Analyst software determines the best route by using an algorithm which finds the shortest path, developed by Edgar Dijkstra (1959). Dijkstra's algorithm is the simplest path finding algorithm, even though these days a lot of other algorithms have been developed. Dijkstra's algorithm reduces the amount of computational time and power needed to find the optimal path. The algorithm strikes a balance by calculating a path which is close to the optimal path that is computationally manageable (Olivera 2002).

The algorithm breaks the network into nodes (where lines join, start or end) and the paths between such nodes are represented by lines. In addition, each line has an associated cost representing the cost (length) of each line in order to reach a node. There are many possible paths between the origin and destination, but the path calculated depends on which nodes are visited and in which order. The idea is that, each time the node, to be visited next, is selected after a sequence of comparative iterations, during which, each candidate-node is compared with others in terms of cost (Stewart 2004). The following comprehensible example, which is an application of the algorithm on a case of 6 nodes connected by directed lines with assigned costs, explains the steps between each iteration of the algorithm (Figure 1). The shortest path from node 1 to the other nodes can be found by tracing back predecessors (bold arrows), while the path's cost is noted above the node.

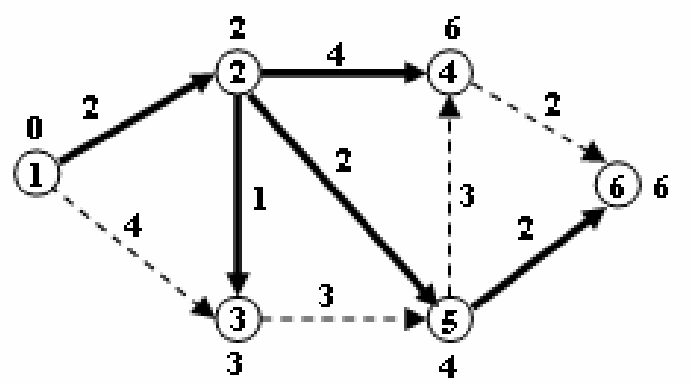

Figure 1: An example of Dijkstra's algorithm (Orlin 2003).

Each node is processed exactly once according to an order that is being specified below. Node 1 (i.e. origin node) is processed first. A record of the nodes that were processed is kept, call it Queue (Table 1). So initially Queue $=\{1\}$. When node $\mathrm{k}$ is processed the following task is performed: If the path's cost from the origin node to $\mathrm{j}$ could be improved including the vertex $(\mathrm{k}, \mathrm{j})$ in the path then, an update follows both of Distance[j] with the new cost and Predecessors[j] with $\mathrm{k}$, where $\mathrm{j}$ is any of the unprocessed nodes and Distance[] is the path's cost from the origin node to $\mathrm{j}$. The next node to be processed is the one with the minimum Distance[], in other words is the nearest to the origin node among all the nodes that are yet to be processed. The shortest route is found by tracing back predecessors.
Table 1: A record, called Queue, with all processed nodes.

\begin{tabular}{|l|c|c|c|c|c|c|c|c|c|c|c|c|}
\hline & \multicolumn{9}{|c|}{ Distance } & \multicolumn{6}{|c|}{ Predecessors } \\
\hline Queue & $\begin{array}{c}\text { Next } \\
\text { node }\end{array}$ & $\mathbf{1}$ & $\mathbf{2}$ & $\mathbf{3}$ & $\mathbf{4}$ & $\mathbf{5}$ & $\mathbf{6}$ & $\mathbf{2}$ & $\mathbf{3}$ & $\mathbf{4}$ & $\mathbf{5}$ & $\mathbf{6}$ \\
\hline 1 & 2 & - & 2 & 4 & $\infty$ & $\infty$ & $\infty$ & & & & & \\
\hline 1,2 & 3 & - & - & 3 & 6 & 4 & $\infty$ & & 2 & 2 & 2 & \\
\hline $1,2,3$ & 5 & - & - & - & 6 & 4 & $\infty$ & & & & & \\
\hline $1,2,3,5$ & 4 & - & - & - & 6 & - & 6 & & & & & 5 \\
\hline $1,2,3,5,4$ & 6 & - & - & - & - & - & 6 & & & & & \\
\hline $1,2,3,5,4,6$ & - & - & - & - & - & - & - & & & & & \\
\hline
\end{tabular}

Network Analyst can be very useful in a variety of sections (ESRI 2006) in our daily life, such as in:

- Business, scheduling deliveries and installations while including time window restrictions, or calculating drive time to determine customer base, taking into account rush hour versus midday traffic volumes.

- Education, generating school bus routes honoring curb approach and no U-turn rules.

- Environmental Health, determining effective routes for county health inspectors.

- Public Safety, routing emergency response crews to incidents, or calculating drive time for first responder planning.

- Public Works, determining the optimal route for point-to-point pickups of massive trash items or routing of repair crews.

- Retail, finding the closest store based on a customer's location including the ability to return the closest ranked by distance.

- Transportation, calculating accessibility for mass transit systems by using a complex network dataset.

\section{CASE STUDY}

In this research work, a small part of Attica's prefecture (a suburb of Athens) was chosen as the case study area. The municipality of Athens is empirically divided into about 30 districts each of which has several solid waste collecting programs for the daily needs of the city. However, there are cases where the standard waste garbage trucks are unable to remove certain pieces of refuse, because of varied restrictive reasons, like size (e.g. furniture, electrical devices, debris). Briefly, this kind of refuse is consisted of really heavy or bulky things whose exposure to air is almost never challenging to the hygienic standards. That's why it is not essential for the refuse to be collected immediately, unless they cause circulatory problems. In this special occasion, the piece of refuse must be collected the moment that it is reported.

Therefore, the municipality has retained a modified truck for each district. The concept is that the standard daily waste collecting programs report to the Municipal 
Solid Waste Department (MSWD) every location that was unable to collect. The MSWD processes the information for each district and decides on the procedure that will be followed. An average scenario for a district is that its assigned truck makes two weekly trips and that each time it visits around 15 locations. Figure 2 illustrates one of these districts, in which a truck is in charge of the waste collection of large items collection. The particular truck must visit all the reported locations in order to complete its collection program.

The examined area is about $1.34 \mathrm{~km}^{2}$, with a population of more than 20,000 citizens and a production of about 5,000 tones of urban refuse per year. The data concerning the area under examination was obtained from the pertinent MSWD of Athens. The data includes maps of the examined area with the correspondent annotation (address and numbering labels of streets), the building blocks and the locations of the waste large items to be collected.

\section{PROPOSED SOLUTION}

This paper describes a study of planning vehicle routes for the waste collection of large items in a district of Athens using Network Analyst - a user-friendly extension of ArcGIS, which provides efficient routing solutions in a simple and straightforward manner. This case study models a real-life scenario which took place in January 2007. That date, the MSWD of Athens acted on a routing plan concerning 15 different locations in the examined area. In order to simulate the situation in ArcGIS, all the relevant information was acquired from MSWD. More precisely, when creating a network routing solution, specific spatial data are needed for the accurate completion of the network. For example, a complete road network, where all the roads within the network are connected, is significant because it allows connection through out the system.

Information regarding the waste collection of large items is gathered through reports by the Municipality of Athens (MoA), which then decides on the procedure to be followed. In order to determine the optimum route an accurate geographic information database system is created with all the needed types of spatially related parameters. These parameters involve static and dynamic data, such as positions of the aforementioned large items, road network, related traffic and population density, etc.

Network Analyst gives the user the ability to produce a map and directions for the quickest route among several locations. The user can define the locations either manually or through a database with the approximate locations in respect to geographic coordinates - this database includes information such as the address and street name for each location. Here, the second way was selected to distribute the locations, after acquiring them from MSWD. Furthermore, in Network Analyst, the routes can be calculated either by user variables such as the distance of each segment or the drive time for each segment. Considering that this kind of refuse collection always takes place during the night shift, the volume of traffic in the roads is inconsiderable, so the results of Network Analyst were generated taking into account the distance criterion.

Therefore, the Network Analyst is used to estimate interrelations between dynamic factors, like network traffic changes (closed roads due to natural or technical causes, for example, fallen trees, car accidents, etc) in residential and commercial areas in a 24 hour schedule, and to produce optimized solutions. The user, in the proposed system, is able to define or modify all required dynamic factors for the creation of an initial scenario. By modifying these particular parameters, alternative scenarios can be generated leading to several solutions. Finally, the optimal solution is identified by a function that refers to various parameters, like the shortest distance, road network as well as social and environmental implications. The calculated waste collection route is then displayed on the screen and a file consisted of the directions to drive through the specified route is created.

\section{RESULTS}

Figure 2 illustrates the addresses of the reported locations (i.e. the loading spots) as they were pointed out on the map using the Network Analyst application.

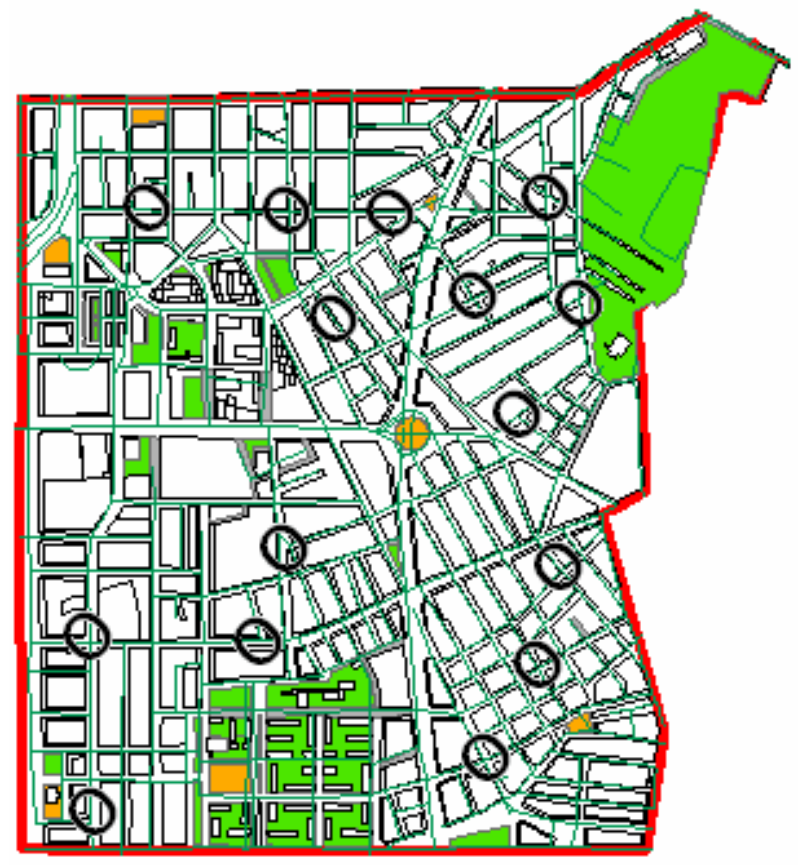

Figure 2: The reported locations of the waste large items in the area under study.

Afterwards, some essential restrictions were taken into account, such as the streets' directions, no U-Turns rules 
(with the exception of the dead-ends) and also, the fact that the truck should follow true-shape route (i.e. it mustn't pass over the squares).

Moreover, Network Analyst was asked to show the results in meters, as the distance criterion was selected, and to reorder the stop-points in order to find the shortest route. It is worth mentioning that, in the special case where some piece of refuse causes traffic problems, Network Analyst can be asked to find the shortest route starting from this certain point, so as to relieve the traffic.

Finally, pushing the "solve" button of Network Analyst, the closest route for the large items collection was produced. This proposed route is illustrated in Figure 3. The stop-points were numbered automatically by Network Analyst in the order they were visited. The stop-points were slightly moved from their original position (see Figure 2) for benefits of distinctness.

As it was mentioned above, Network Analyst calculates the optimal route by means of Dijkstra's Algorithm. In particular, ArcGIS Network Analyst's route solver attempts to find a way through the set of stops with minimum cost. It first computes an asymmetric origindestination cost matrix holding the travel times between the stops using the Dijkstra's algorithm. It then, applies an insertion algorithm to construct an initial solution. At each step, the insertion algorithm inserts the least-cost unvisited stop into the current partial solution (Rice, 2006).

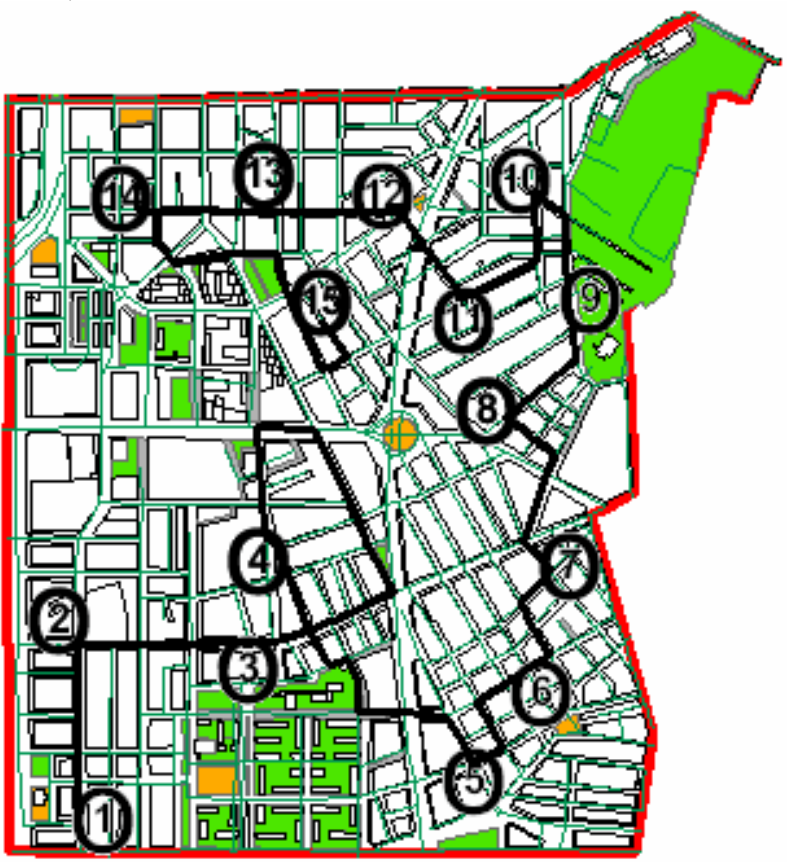

Figure 3: The optimal route for the waste collection of the large items.

In the present, the municipality of Athens decides on the large items collection route empirically. That particular date, the truck covered almost $5.7 \mathrm{~km}$, according to the
MSWD, while the Network Analyst's proposed route was just $4.592 \mathrm{~km}$ long. The experimental results demonstrate that significant savings compared to the current practice can be obtained with the use of a computerized software optimization.

In this scenario, an optimization of $20 \%$ is succeeded, comparatively to the empiric method that the MSWD has used so far. Thus, the implementation of the newly proposed collection route design by means of GIS would be conducive to both cost and time savings.

\section{DISCUSSION AND FUTURE WORK}

Computation of shortest paths is a famous area of research in Computer Science, Operations Research and GIS. There is a great number of ways to calculate shortest paths depending on the type of network and problem specification. Network Analyst is not only capable to reproduce a satisfying number of scenarios, but also it has the ability to be easily adapted to new conditions.

In the future, we are looking forward to inquire, if it is in our interest, the extension of the use of Network Analyst in the daily solid waste collecting programs in the municipality of Athens. The route that the trucks follow so far, is empirically calculated, too.

\section{REFERENCES}

Dijkstra, E.W., 1959. "A note on two problems in connexion with graphs". Numerische Mathematik, 1, 269-271.

Dorigo, M., Di Caro, G., Gambardella, L.M., 1999. "Ant Algorithms for Discrete Optimization". Artificial Life, 5(2), 137-172.

ESRI, GIS and Mapping Software Support Group, 2006. "ArcGIS Network Analyst: Routing, Closest Facility, and Service Area Analysis". http://www.esri.com/networkanalyst (Accessed on February 10, 2007).

GEOLORE (2003): Development of a Geographical Information System for the organization and implementation of an integrated waste management at a local and/or regional level. http://aix.meng.auth.gr/geolore (Accessed on February 10, 2007).

Glover, F., Laguna, M., 1997. "Tabu Search”. Kluwer, Norwell, MA

Holland, J.H., 1975. "Adaptation in Natural and Artificial Systems", University of Michigan Press.

Karagiannidis A., Perkoulidis G., Erkut E., Tjandra S., 2006. «Optimization of urban solid waste collection through GIS use: A part implementation for the Municipalities of Panorama and Sikies". $21^{\text {st }}$ European Conference for ESRI Users.

Kirkpatrick, S., Gelatt, C.D., Vecchi, M.P., 1983. "Optimization by Simulated Annealing, Science". 220 (4598), 671-680.

Lakshumi, A.P.Poun, Ramiya, A.M., Ssthya, R., 2006. "Optimal Route Analysis For Solid Waste Disposal Using Geographical Information System". http://www.gisdevelopment.net/proceedings/mapindia/200 
6/student\%20oral/mi06stu_113.htm. (Accessed on February 10, 2007).

Ludwig, H.F., Black, R.J., 1968. "Report on the solid waste problem". Journal of Sanitary Engineering Div. 94 (2), 355-370.

Miller, Ch., 2005. "Brush and Bulky Item Collection Routing Program Comparisons". http://charlotte.utdallas.edu/mgis/prj_wrkshp/2005/Miller/ BABIC_Website_Files/index.html (Accessed on February $10,200 \overline{7})$.

Modak A., Everett, J.S., 1996. "Optimal regional scheduling of solid waste system. II: Model solution", ASCE Journal of Environmental Engineering, 122 (9), 793-799.

Moussiopoulos, N., Karagiannidis, A., Xirogiannopoulou, A., Theodoseli, M., Perkoulidis G., Antonopoulos, J., Malamakis, A., Trenstiou, E., Vlachocostas, Ch., Pardali, S., Tjandra, S., McCartney, D., Leonard, J., Haight, D., 2006. "Using GIS to assess the local problem of Waste Management in an urban area". http://aix.meng.auth.gr/geolore/model/local/local\%20probl em.pdf (Accessed on February 10, 2007).

Nuortioa, T., Kytöjokib, J., Niskaa, H., Bräysy, O., 2005. "Improved route planning and scheduling of waste collection and transport". http://www.sciencedirect.com/science?...3520c6c9ea5\&ie $=/$ sdarticle.pdf (Accessed on February 10, 2007).

Olivera, F., 2002. "Map Analysis with Networks". http://ceprofs.tamu.edu/folivera/GISCE/Spring2002/Presentations/NetworksIntro.ppt (Accessed on February 10, 2007).

Orlin, J., 2003. "Dijkstra's Algorithm Animation". MIT OpenCourseWare, Network Optimization, Spring 2003. http://ocw.mit.edu/NR/rdonlyres/Sloan-School-ofManagement/15-082JNetwork-

OptimizationSpring2003/FC13EFA1-0FE2-4BFB-B0198939606EDDCC/0/dijkstrasalgorithm.pdf (Accessed on February 10, 2007).

Parker M., 2001. "Planning Land Information Technology Research Project: Efficent Recycling Collection Routing in Pictou County". www.cogs.ns.ca/planning/projects/plt20014/images/resear ch.pdf (Accessed on February 10, 2007).

Rice, M., 2006. "ArcGIS Desktop - Extension - Network Analyst forum". http://forums.esri.com/Thread.asp?c=93\&f=1944\&t=1876 $32 \& m c=21 \#$ msgid565389 (Accessed on February 10, 2007).

Stewart, L.A., 2004. "The Application of Route Network Analysis to Commercial Forestry Transportation". http://gis.esri.com/library/userconf/proc05/papers/pap 1309 .pdf (Accessed on February 10, 2007).

\section{AUTHOR BIOGRAPHIES}

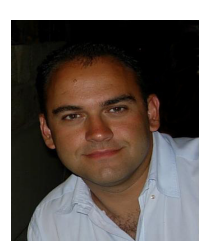

NIKOLAOS V. KARADIMAS was born in Athens, Greece and he graduated from Patra T.E.I. in 1995 with a Bachelor's degree in Electrical Engineering. $\mathrm{He}$ then received a Bachelor's degree with Honours in Electronic Engineering and a Masters degree in Computer Science from Glasgow Caledonian University, Scotland in 1997 and 1998, respectively. He also received a Masters degree in Distributed and Multimedia Information Systems from Heriot-Watt
University, Scotland in 1999. Since 2002 he is a $\mathrm{PhD}$ candidate in National Technical University of Athens. Furthermore, since 2001 he is teaching Informatics in Hellenic Army Academy and New York College, since 2003 he is teaching in T.E.I. of Chalkida and since 2005 he is teaching in Technical NCO Academy, as well. He is a member of the Greek Chamber of Engineers, member of IEEE and member of IEE. His research interests are in the fields of Databases, Optimization Techniques, Geographical Information Systems, Decision Support Systems and Multimedia.

MARIA KOLOKATHI is an under graduate student in the Faculty of Electrical and Computing Engineering of the National Technical University of Athens (NTUA). Her studies are focused on Telecommunications and her diploma thesis is on Geographic Information Systems (GIS).

GERASIMOULA DEFTERAIOU is an under graduate student in the Faculty of Electrical and Computing Engineering in National Technical University of Athens (NTUA). Her studies are focused on Computer Science and Programming Techniques and her diploma thesis is on Geographic Information Systems (GIS).

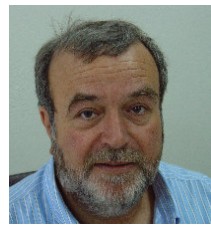

VASSILI LOUMOS received the Diploma of Electrical Engineering and the PhD degree in Computer Science from the National Technical University of Athens (NTUA), Greece in 1975 and 1989. From 1975 to 1978 he was a research engineer at the Centre National de Recherhe Scientifique, Paris, France. From 1980 to 1982 he was with CGEE ALSHTOM as a field engineer. In 1990 he joined the faculty of the School of Electrical \& Computer Engineering of the NTUA where he is presently a professor. $\mathrm{He}$ is teaching Multimedia Technologies and Computer Graphics. His research interests are in the fields of Multimedia, Computer Vision and Internet Navigation. 